\title{
Characterisation of anticytoplasmic antibodies and their clinical associations
}

\author{
Wei-Howe Koh, Juliet Dunphy, Jean Whyte, Jonathan Dixey, Neil John McHugh
}

\begin{abstract}
Objectives-To characterise the cytoplasmic staining patterns identified by indirect immunofluorescence (IF) of human epithelial (HEp-2) cells and the antigens recognised using additional serological techniques. To define the disease associations of anticytoplasmic antibodies.
\end{abstract}

Methods-Sera from 1173 patients were screened for cytoplasmic IF staining on HEp-2 cells and the patterns characterised. The presence of antimitochondrial antibodies (AMA) was evaluated by a sensitive anti-pyruvate dehydrogenase complex enzyme linked immunosorbent assay (ELISA) (IgG) and by immunoblotting. Detection of antibodies to extractable nuclear antigens (ENA) was performed by double immunodiffusion and the presence of anti-ribosomal $P$ antibodies was determined by immunoblotting. Results-Cytoplasmic IF staining was demonstrated in 75 sera $(6 \cdot 4 \%)$. Six different patterns were recognised: coarse granular filamentous speckles (AMA, $n=9)$; condensed large speckles (anti-golgi apparatus antibodies, $n=3$ ); cytoskeletal $(n=9)$; centriolar $(n=4)$; diffuse coarse speckles $(n=33) ;$ and fine speckles $(n=17)$. Of the nine sera with an AMA pattern, the presence of these antibodies was confirmed in seven by the ELISA $(n=6)$ and on immunoblotting $(n=7)$. One of the seven patients had primary biliary cirrhosis, and two had scleroderma. Two patients with anti-golgi antibodies had rheumatoid arthritis and two with anticentriolar antibodies had scleroderma. Of 33 sera that had cytoplasmic staining and were ANA negative, three were positive for anti-Ro and two were positive for anti-Jo-1 antibodies.

Conclusions-In general, defined cytoplasmic IF patterns have no specific disease associations. However, the finding of cytoplasmic fluorescence should not be ignored, as it may indicate the presence of antibodies to ENA in the absence of nuclear staining.

(Ann Rheum Dis 1995; 54: 269-273)

Indirect immunofluorescence (IF) of human epithelial (HEp-2) cells is a standard diagnostic assay for the detection of antinuclear antibodies (ANA). ${ }^{1}$ The use of HEp- 2 cells as a substrate allows the detection of most nuclear and cytoskeletal related autoantibodies in addition to autoantibodies to cytoplasmic antigens such as ribosomes, mitochondria, and golgi apparatus. ${ }^{2}$ Thus the presence of cytoplasmic staining is occasionally seen but, apart from some well defined patterns such as the detection of mitochondria, ${ }^{3}$ the significance of anticytoplasmic antibodies is mostly undetermined. The ANA test is commonly used in rheumatology practice and the presence of a striking cytoplasmic fluorescence pattern, especially in high titres, may lead the clinician to question their relevance to the patient's disease. This study aimed to characterise cytoplasmic staining patterns and the antigens recognised using additional serological techniques and to define their disease associations.

\section{Patients and methods}

The sera of 1173 patients, who were referred to the Royal National Hospital for Rheumatic Diseases, were tested by our serology service for ANA by indirect IF using HEp-2 cells, and screened for the presence of cytoplasmic fluorescence. The patients had a wide spectrum of rheumatic diseases for which an ANA test was clinically indicated. These included systemic lupus erythematosus (SLE, 12\%), rheumatoid arthritis (RA, 12\%), primary Sjögren's syndrome $(4 \%)$, scleroderma $(4 \%)$, systemic vasculitis $(1 \%)$, Raynaud's disease $(1 \%)$, polymyositis/dermatomyositis (PM/DM, $0.8 \%$ ), and a variety of rheumatic disorders $(13 \cdot 2 \%)$. The diagnoses of the remaining patients were either not given (14\%) or not established $(38 \%)$. Those sera which produced a cytoplasmic IF stain were further evaluated by immunodiffusion and immunoblotting for autoantibodies to cytoplasmic antigens. The clinical diagnoses of the patients with anticytoplasmic antibodies were determined by review of their case notes.

\section{IMMUNOFLUORESCENCE}

The sera were diluted $1 / 40$ in phosphate buffered saline (PBS) and incubated on HEp-2 cells (Biodiagnostic Ltd, Worcs, UK) for 30 minutes at room temperature. The slides were then washed in PBS and incubated with fluorescein isothiocyanate (FITC) conjugated polyvalent goat anti-human immunoglobulin (1/150 dilution) for 30 minutes at room temperature. The observed cytoplasmic IF patterns were then characterised. 


\section{IMMUNODIFFUSION}

Precipitating antibodies against extractable nuclear antigens (ENA) were detected by means of double immunodiffusion in Ouchterlony plates containing $1 \%$ agarose. Saline extracts of calf thymus prepared as previously described, ${ }^{4}$ fresh extracts of rabbit thymus powder (Pel-Freeze, Rogers, AR, USA) and commercially produced Ro/La extract (Bradshaw Biologicals Ltd, Leics, UK) were used as sources of antigen. Antibody specificity was defined using a variety of prototype sera, including those with antibodies to U1RNP, Sm, Ro(SS-A), La(SS-B) and Jo-1 antigens.

PDHC ELISA AND IMMUNOBLOTTING

We tested all sera which produced cytoplasmic fluorescence for antimitochondrial antibodies (AMA) by a sensitive anti-pyruvate dehydrogenase complex (PDHC) enzyme linked immunosorbent assay (ELISA) as previously described. ${ }^{5}$ Those sera that had coarse granular filamentous speckled IF patterns characteristic of AMA, or increased AMA on the ELISA were further evaluated by immunoblotting which has been previously described. ${ }^{6}$ Purified human brain mitochondria was used as a source of antigen for immunoblotting. All sera that produced a cytoplasmic fluorescence were also tested for the recognition of ribosomal $\mathbf{P}$ antigen by immunoblotting using a whole cell extract prepared from K562 cells.

\section{Results}

IMMUNOFLUORESCENCE

Of 1173 sera tested, $75(6 \cdot 4 \%)$ had cytoplasmic fluorescence staining. Figure $1 \mathrm{~A}-\mathrm{F}$ shows the six patterns that were identified. The commonest pattern was the diffuse coarse speckled (A), which occurred in $44 \%(n=33)$

Cytoplasmic immunofluorescence patterns and associated diagnoses

\begin{tabular}{|c|c|c|c|}
\hline Pattern & $\begin{array}{l}\text { Total } \\
\text { No }\end{array}$ & Diagnosis & No \\
\hline Diffuse coarse speckles & 33 & $\begin{array}{l}\text { SLE } \\
\text { RA } \\
\text { Polymyositis } \\
\text { PMR } \\
\text { Limited SS } \\
\text { Diffuse SS } \\
\text { Siögren's disease } \\
\text { Others }\end{array}$ & $\begin{array}{r}5 \\
2 \\
2 \\
2 \\
1 \\
1 \\
1 \\
19\end{array}$ \\
\hline Diffuse fine speckles & 17 & $\begin{array}{l}\text { SLE } \\
\text { Sjögren's disease } \\
\text { Diffuse SS } \\
\text { Others }\end{array}$ & $\begin{array}{l}5 \\
3 \\
2 \\
7\end{array}$ \\
\hline Cytoskeletal & 9 & $\begin{array}{l}\text { RA } \\
\text { SLE } \\
\text { Diffuse SS } \\
\text { Dermatomyositis } \\
\text { Others }\end{array}$ & $\begin{array}{l}2 \\
2 \\
1 \\
1 \\
3\end{array}$ \\
\hline $\begin{array}{l}\text { Coarse granular filamentous speckles } \\
\text { (antimitochondrial antibodies) }\end{array}$ & 9 & $\begin{array}{l}\text { Limited SS } \\
\text { SLE } \\
\text { PBC } \\
\text { Others }\end{array}$ & $\begin{array}{l}2 \\
1 \\
1 \\
5\end{array}$ \\
\hline Anticentriolar antibodies & 4 & $\begin{array}{l}\text { Diffuse SS } \\
\text { PMR } \\
\text { Others }\end{array}$ & $\begin{array}{l}2 \\
1 \\
1\end{array}$ \\
\hline $\begin{array}{l}\text { Condensed large speckles } \\
\text { (anti-golgi antibodies) }\end{array}$ & 3 & $\begin{array}{l}\text { RA } \\
\text { Others }\end{array}$ & $\begin{array}{l}2 \\
1\end{array}$ \\
\hline
\end{tabular}

SLE = Systemic lupus erythematosus; $R A=$ rheumatoid arthritis; $P M R=$ polymyalgia rheumatica; SS = systemic sclerosis; PBC = primary biliary cirrhosis; Others include undifferentiated connective tissue disease, seronegative arthritis, and vasculitis. of the sera that tested positive for cytoplasmic IF (table). Cytoplasmic fluorescence patterns that were infrequently encountered were those characteristic for the anti-golgi antibodies (C) $(n=3)$, and anticentriolar antibodies (B) $(n=4)$. Altogether, 33 of the 75 sera were ANA negative.

\section{IMMUNODIFFUSION}

Autoantibodies to ENA were detected in 10 of the sera with anticytoplasmic antibodies, five of which had a diffuse coarse speckled pattern. Five had anti-Ro (SS-A) antibodies, four had anti-Jo-1 antibodies and another had anti-U1 ribonucleoprotein (RNP) antibodies. Of the five sera that had anti-Ro antibodies, one also had anti-La antibodies and another had both AMA and anti-La antibodies. Five of the patients who had autoantibodies to ENA (anti-Ro, $\mathrm{n}=3$; anti-Jo-1, $\mathrm{n}=2$ ) were ANA negative.

PDHC ELISA

Of the nine sera with AMA IF pattern, six had antibodies detected by the sensitive antiPDHC ELISA (IgG). Figure 2 shows the results of the anti-PDHC ELISA of the 75 test sera and of 38 healthy controls. A cut off of 2 SD from the mean of the healthy control was used to determine a positive result. Three patients who did not have an AMA IF pattern were tested positive for antibodies to PDHC by the ELISA.

\section{IMMUNOBLOTTING}

Seven of the nine sera that produced an AMA IF recognised both a $70 \mathrm{kDa}$ and a $52 \mathrm{kDa}$ polypeptide on immunoblotting (fig 3). Of these seven patients, six had antibodies to PDHC detected on the ELISA. None of the three patients who had a negative AMA IF but were positive for antibodies to PDHC by ELISA recognised a $70 \mathrm{kDa}$ mitochondrial antigen on immunoblotting. No sera had antibodies against the cytoplasmic antigen ribosomal $\mathrm{P}$ detected by immunoblotting.

\section{CLINICAL ASSOCIATIONS}

The table lists the various cytoplasmic IF patterns identified and the associated clinical diagnoses. Amongst those patients who had a coarse granular filamentous speckled pattern characteristic of the presence of AMA, one patient had primary biliary cirrhosis (PBC) and two had limited systemic sclerosis. Another patient with generalised osteoarthritis had increased serum alkaline phosphatase without other clinical evidence of PBC or scleroderma.

Two of the three patients with anti-golgi antibodies had seropositive RA, whilst two patients with anticentriolar antibodies had scleroderma. The diffuse coarse or fine speckled and cytoskeletal patterns were identified in patients with a variety of rheumatic conditions (table) and no disease specificities were noted. 

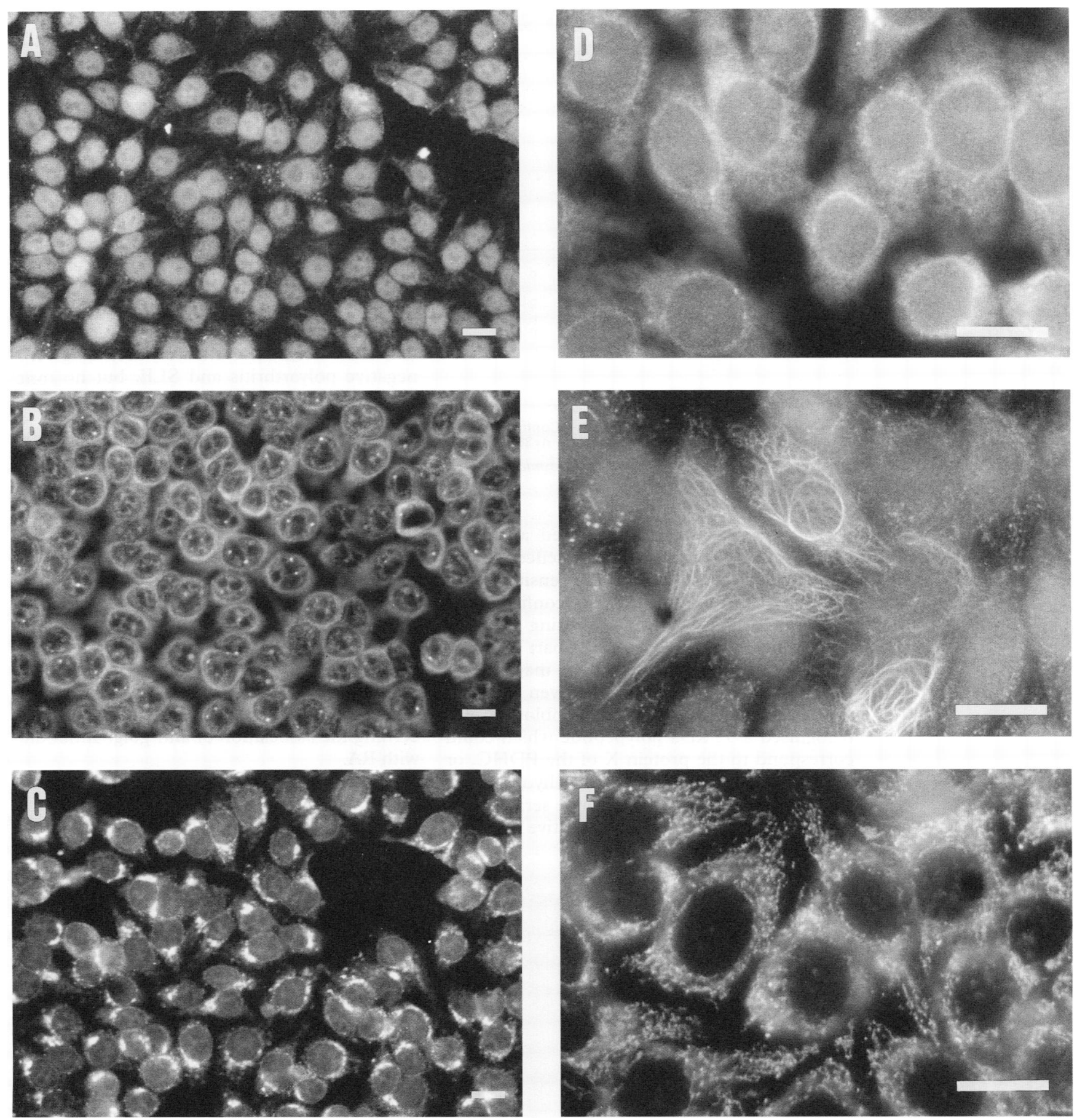

Figure 1 Cytoplasmic fluorescence patterns on human epithelial (HEp-2) cells. A: Diffuse cytoplasmic coarse speckled pattern. B: Anticentriolar antibodies pattern. C: Condensed large speckles (anti-golgi antibodies). D: Diffuse cytoplasmic fine speckled pattern. E: Cytoskeletal pattern. F: Coarse granular filamentous speckles (antimitochondrial antibodies). Bars represent $100 \mu \mathrm{m}$.

\section{Discussion}

Our results show that cytoplasmic fluorescence is not an infrequent finding when ANA is tested for by indirect IF of HEp-2 cells. About one in 20 sera $(6 \cdot 4 \%)$ produced a cytoplasmic IF stain. We have identified six cytoplasmic IF patterns, including some well defined patterns like those characteristic of $\mathrm{AMA}^{3}{ }^{3}$ anti-golgi, ${ }^{7}$ anticentriolar, ${ }^{8}$ and anticytoskeletal antibodies. ${ }^{9}$ The most common pattern found was a diffuse coarse speckled pattern, which occurred in almost half the sera which had a cytoplasmic stain. Diffuse fine speckled and cytoskeletal patterns occurred less frequently. These patterns were produced by sera from patients with a spectrum of rheumatic diseases.
By using an indirect IF method with PTK 2 cells fixed with paraformaldehyde and digitonin as substrate, Senécal et $a l^{9}$ found a high frequency of antibodies to intermediate filaments (one of three classes of cytoskeleton complex network of filaments) in patients with PM/DM, RA, systemic sclerosis, and SLE. In contrast to Senécal et al, who were unable to demonstrate the presence of these antibodies using HEp-2 cells as substrate, we were able to detect anticytoskeletal antibodies in patients with a similar profile of autoimmune diseases (table). Similarly, Osung et al, ${ }^{10}$ using HEp-2 cells as substrate, detected antibodies against intermediate filaments of the cytoskeleton in patients with RA. 


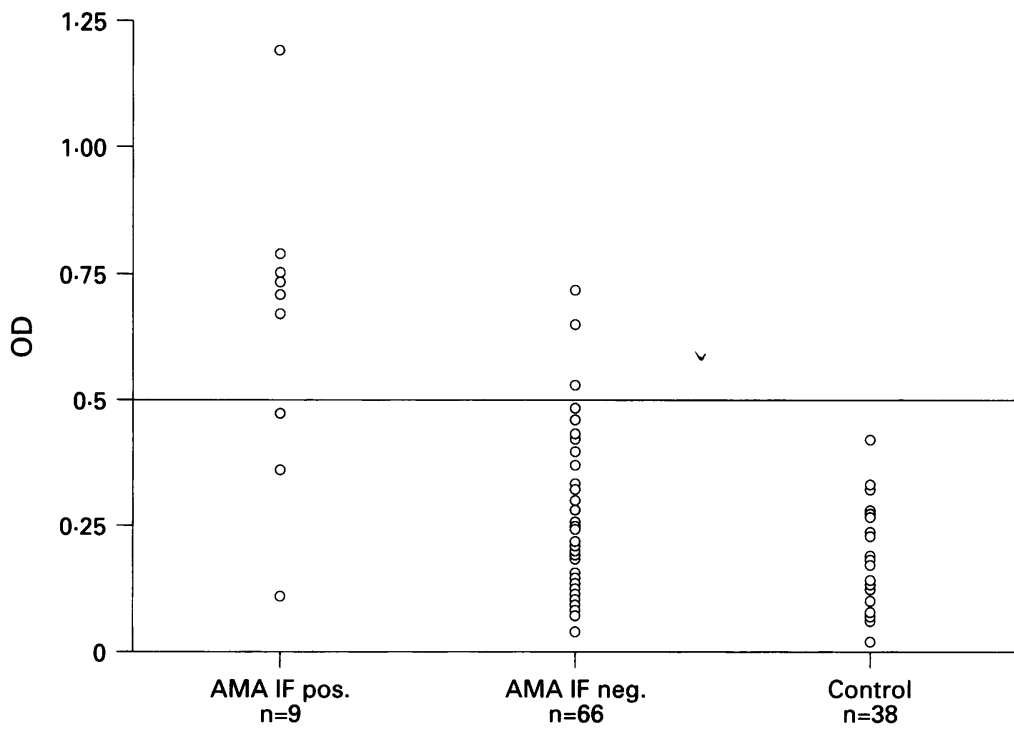

Figure 2 Detection of antimitochondrial antibodies in sera with anticytoplasmic antibodies using a sensitive anti-pyruvate dehydrogenase complex IgG ELISA.

In the nine sera which showed a characteristic AMA pattern, the presence of the antibodies was detected by the sensitive antiPDHC ELISA in six and was confirmed by immunoblotting in seven using human brain mitochondrial antigen. ${ }^{11}$ Apart from the $70 \mathrm{kDa}$ polypeptide which is the major mitochondrial antigen in PBC, the seven sera that were positive for AMA on immunoblotting also recognised a $52 \mathrm{kDa}$ polypeptide which could correspond to the protein $\mathrm{X}$ of the PDHC, or the branched chain keto acid dehydrogenase complex (BCODH) ${ }^{11}$ Of the nine sera with an AMA IF pattern, two were negative for anti-

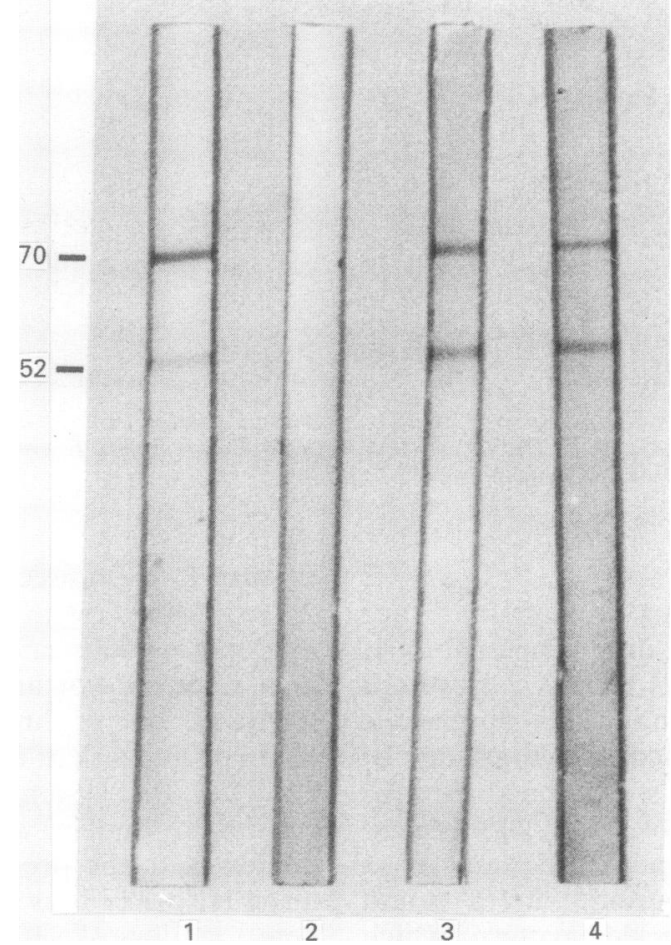

Figure 3 Recognition of human mitochondria antigen by AMA positive sera on immunoblotting. Lane 1: Positive $A M A$ control serum showing reactivity with $70 \mathrm{kDa}$ and $52 \mathrm{kDa}$ antigen. Lane 2: Normal control serum. Lane 3: Positive AMA test serum. Lane 4: Positive AMA test serum. bodies to PDHC on the ELISA and did not recognise either the $72 \mathrm{kDa}$ or the $52 \mathrm{kDa}$ polypeptide on immunoblotting. Although the two sera demonstrated a characteristic AMA IF pattern, the nature of the cytoplasmic antigens was not determined.

The presence of autoantibodies to mitochondrial antigens has been described in the majority of patients with $\mathrm{PBC}^{12}$ and up to $25 \%$ of patients with systemic sclerosis. ${ }^{13}$ Patients with other autoimmune diseases may also have AMA. ${ }^{14}$ In our study, of those patients who had AMA IF staining patterns, two had limited systemic sclerosis and one had PBC. The remainder of the patients with AMA IF pattern had other rheumatic diseases, including seronegative polyarthritis and SLE, but no overt liver disease; nevertheless, the patients may have had subclinical liver disease. ${ }^{15}$

A condensed large speckled cytoplasmic IF pattern characteristic for anti-golgi antibodies was not a pattern commonly detected. Only three of the 1173 sera tested exhibited this pattern-a prevalence rate similar to that reported in other studies. ${ }^{716}$ The antibody was first reported by Rodriquez et al in a patient with Sjögren's syndrome and lymphoma. ${ }^{17}$ Subsequently, the antibody was found to be associated with other rheumatic diseases, ${ }^{7}$ including RA. ${ }^{16}$ Of our three patients with the antibody, two had seropositive RA, supporting the report by Hong et al ${ }^{16}$ concerning the association of anti-golgi antibodies with RA.

The IF pattern typical of anticentriolar antibodies was detected in two of our patients with scleroderma-an association described previously. ${ }^{8}$ However, the pattern is not specific to the disease, as it was also seen in a patient with polymyalgia rheumatica and another with mixed connective tissue disease, both of whom did not have features of scleroderma.

We were able to detect autoantibodies to ENA (anti-Ro, anti-La, anti-Jo-1 and anti-U1 RNP) in some of the sera with cytoplasmic fluorescence. Ro and La antigens shuttle between cellular compartments and may be found in the cytoplasm in association with RNA complexes. ${ }^{18}$ These antigens have been termed soluble cytoplasmic RNP (scRNP) ${ }^{18}$ and may have been responsible for some of the cytoplasmic fluorescence detected. The antigen Jo-1, which is a cytoplasmic enzyme histidyl tRNA synthetase, can also give rise to a cytoplasmic IF stain on HEp-2 cells. ${ }^{19} \mathrm{We}$ found that the majority of sera with antibodies to ENA tended to be associated with a diffuse coarse cytoplasmic IF pattern. Of interest, five of the sera with these antibodies were negative for ANA on IF. Thus it is important not to disregard cytoplasmic fluorescence in the absence of nuclear staining, as this may indicate the presence of antibodies to ENA. ${ }^{2}$

Antibodies to the cytoplasmic antigen ribosomal $\mathbf{P}$ protein occur predominantly in patients with $S L E^{20}$ and it is thought that they often account for cytoplasmic IF ${ }^{21}$ Using the specific Western blot technique, ${ }^{22}$ we did not detect anti-ribosomal $\mathrm{P}$ antibodies in any of 
our patients, some of whom had SLE. This may have resulted from their relatively low prevalence which varies between 5 and $20 \%$ of patients with SLE. ${ }^{23}{ }^{24}$ Furthermore, the antibody titre may vary with time $e^{25}$ and is higher in those patients with active disease ${ }^{26}$ - a feature not necessarily present in our patients.

In conclusion, although, in general, anticytoplasmic antibodies are not disease specific, certain characteristic patterns on IF are of more diagnostic help than others. Furthermore, a negative ANA result may sometimes be misleading if the cytoplasmic IF is ignored.

Dr W $\mathrm{H}$ Koh is a visiting fellow funded by the Singapore government.

1 Maddison P J. Autoantibody profile. In: Maddison P J, Isenberg D A, Woo P, Glass D N, eds. Oxford textbook of rheumatology. New York: Oxford University Press, 1993, 389-96.

2 McCarthy G A. Autoantibodies and their relation to rheumatic diseases. Med Clin North Am 1986; 70: 237-61.

3 Walker J G, Doniach D, Roitt I M, Sherlock S. Serologica tests in diagnosis of primary biliary cirrhosis. Lancet 1965 i: $827-31$.

4 Clark G, Reichlin M, Tomasi T B Jr. Characterization of a soluble cytoplasmic antigen reactive with sera from patients with systemic lupus erythematosus. F Immunol patients with systemic

5 McHugh N J, James I E, Fairburn K, Maddison P J. Autoantibodies to mitochondrial and centromere antigens in primary biliary cirrhosis and systemic sclerosis. Clin in primary biliary cirrhosis and

6 McHugh N J, James I E, Maddison P J. Differential isotype recognition of two centromere associated polypeptides by immunoblotting in connective tissue disease. Clin Exp Immunol 1988; 72: 457-64

7 Fritzler M J, Etherington, J, Sokoluk C, Kinsella T D, Valencia D W. Antibodies from patients with autoimmune disease react with a cytoplasmic antigen in the golgi apparatus. F Immunol 1984; 132: 2904-8.

8 Tuffanelli D L, McKeon F, Kleinsmith D M, Burnham T K, Kirschner $M$. Anticentromere and anticentriole antibodies in the scleroderma spectrum. Arch Dermatol 1983; 119: $560-6$.

9 Senécal J L, Oliver J M, Rothfield N. Anticytoskeletal autoantibodies in the connective tissue diseases. Arthritis Rheum 1985; 28: 889-98.
10 Osung O A, Chandra M, Holborow E J. Antibody to intermediate filaments of the cytoskeleton in rheumatoid intermediate filaments of the cytoskeleton
arthritis. Ann Rheum Dis 1982; 41: 69-73.

11 Whyte J, Hough D, Maddison P J, McHugh N J. The association of primary biliary cirrhosis and systemic sclerosis is not accounted for by cross reactivity between mitochondrial and centromere antigens. $f$ Autoimmunity 1994; 7: 413-24.

12 Lindenborn-Fotinos J, Baum H, Berg B A. Mitochondrial antibodies in primary biliary cirrhosis: species and nonspecies specific determinants of M2 antigen. Hepatolog 1985; 5: 763-9.

13 Gupta R C, Seibold R J, Krishnan M R, Steigerwald J C. Precipitating autoantibodies to mitochondrial proteins in progressive systemic sclerosis. Clin Exp Immunol 1984; 57: progres.

14 Mouritsen S, Demant E, Permin H, Wiik A. High prevalence of anti-mitochondrial antibodies among patients with some well defined connective tissue diseases. Clin Exp Immunol 1986; 60: 68-76.

15 Walker J G, Doniach D, Doniach I. Mitochondrial antibodies and subclinical liver disease. $Q \mathcal{F}$ Med 1970; 39 $31-48$.

16 Hong H S, Morshed A S, Tanaka S, Fujiwara T, Ikehara Y, Nishioka M. Anti-golgi antibody in rheumatoid arthritis patients recognizes a novel antigen of $79 \mathrm{kDa}$ (doublet) by Western blot. Scand f Immunol 1992; 36: $785-92$.

17 Rodriguez J L, Gelpi C, Thomson T M, Real F J Fernandez J. Anti-Golgi complex autoantibodies in a patient with Siögren's syndrome and lymphoma. Clin Exp patient with Sjögren's syndrom

18 Hardin J A, Rahn D R, Shen C, et al. Antibodies from patients with connective tissue diseases bind specific subsets of cellular RNA-protein particles. $\mathcal{f}$ Clin Invest 1982; 70: 141-7.

19 Reichlin M, Arnett F C. Multiplicity of antibodies in myositis sera. Arthritis Rheum 1984; 27: 1150-6.

20 Teh L S, Isenberg D A. Antiribosomal P protein antibodies in systemic lupus erythematosus. A reappraisal. Arthritis Rheum 1994; 37: 307-15.

21 Tan E M. Autoantibodies in systemic lupus erythematosus. In: McCarthy D J, Koopman W J, eds. Arthritis and allied conditions, Vol 2. Philadelphia: Lea and Febiger, 1993; conditions,

22 Bonfa E, Elkon K B. Clinical and serologic associations of the antiribosomal P protein antibody. Arthritis Rheum 986; 29: 981-5.

23 Elkon K B, Parnassa A P, Foster C L. Lupus autoantibodie target ribosomal $\mathrm{P}$ proteins. $\mathcal{f}$ Exp Med 1985; 162: 459-71.

24 Francoeur A M, Peebles C L, Heckman K J, Lee J C, Tan E M. Identification of ribosomal protein autoantigens. F Immunol 1985; 135: 2378-84.

25 Craft J, Hardin J A. Antinuclear antibodies. In: Kelley W N, Harris E D Jr, Ruddy S, Sledge C B, eds. Textbook of rheumatology. Philadephia: W B Saunders, 1993; 164-87.

26 Sato T, Uchiumi T, Ozawa T, et al. Autoantibodies against ribosomal proteins found with high frequency in patients with systemic lupus erythematosus with active disease. $\mathcal{F}$ Rheumatol 1991; 18: 1681-4. 